\title{
Temporal stability of primate scent samples
}

\author{
Alice C. Poirier ${ }^{1,2}$ (D) John S. Waterhouse ${ }^{2} \cdot$ Jacob C. Dunn ${ }^{2,3,4} \cdot$ Andrew C. Smith ${ }^{2}$
}

Received: 14 September 2020 / Accepted: 27 February 2021 / Published online: 12 March 2021

(C) The Author(s) 2021 OPEN

\begin{abstract}
A common recommendation in the field of animal chemosignaling is to store and transport scent samples frozen, since they are likely to change with time and degrade due to bacterial activity inside the sample containers and the loss of the most volatile compounds. However, we still ignore the exact pattern of change or degradation for these types of samples. Here we experimentally tested the stability of primate scent samples during analytical procedures. For this purpose, we used swabs of naturally deposited glandular secretions from captive tamarins (Neotropical primates) analyzed by headspace gas chromatography-mass spectrometry. We successively extracted the samples by solid-phase microextraction, while controlling for the delay between extractions, and compared the number of compounds detected in the samples under each condition. We found that compounds were lost and transformed over time inside the sample vials. Such natural decay of scent signals is likely to contribute to the long term information transmitted. We found no evidence that long delays at room temperature affected sample chemical composition more than short delays. Nonetheless, we showed that repeated extraction of a sample increased the loss of compounds. The changes in sample chemical composition observed over time in this experiment support standard recommendation to avoid storing samples for long periods at room temperature and to extract each sample only once, in order to ensure optimum results.
\end{abstract}

Keywords Chemosignaling · GC-MS · Sample degradation · Solid-phase microextraction · Volatile organic compounds

\section{Introduction}

Olfactory communication in animals involves semiochemicals, which can provide conspecifics with information on an individual's identity, as well as its social, reproductive, and health status. Volatile, semi- and non-volatile organic compounds produced by the signaler are liberated into the environment, either via passive exudation of body odors or excretions, or via active deposition of scent gland secretions during scent-marking, and can constitute interand intra-specific cues and signals [1]. To this day, the most commonly used method for the collection and analysis of animal semiochemicals is to collect odor samples on swabs made of cotton or viscose, which are then stored in air-tight chromatography vials [1, 2]. Other collection methods include thermal desorption and portable devices able to detect the chemical components of an odor in situ [3]. Compounds are then generally extracted from the substrate by contact with a solvent or an absorbent material. The latter can have a range of polarities, such as non-polar polydimethylsiloxane (PDMS) and the more polar divinylbenzene (DVB), and can be incorporated into a solid-phase microextraction (SPME) fiber. Analysis by gas chromatography-mass spectrometry (GC-MS) commonly follows.

The existing literature on animal chemosignaling commonly recommends researchers to store and transport

Supplementary Information The online version contains supplementary material available at https://doi.org/10.1007/s42452-021-04455 -1 .

$\bowtie$ Alice C. Poirier, alice.poirier@ucalgary.ca| ${ }^{1}$ Department of Anthropology and Archaeology, University of Calgary, Calgary, Canada. ${ }^{2}$ School of Life Sciences, Anglia Ruskin University, Cambridge, UK. ${ }^{3}$ Biological Anthropology, Department of Archaeology, University of Cambridge, Cambridge, UK. ${ }^{4}$ Department of Cognitive Biology, University of Vienna, Vienna, Austria. 
swab samples frozen $[2,4,5]$. The reason for this lies in the fact that at room temperatures, the high volatilities of some of the compounds present makes them susceptible to loss by evaporation; and the microbiological activity inside the sample container produces its own volatile components, which can contaminate the original sample. Nevertheless, the exact pattern of degradation for these scent samples is not known [6]. Here we experimentally tested patterns of sample decay, using swabs of naturally deposited glandular secretions from captive tamarins (Callitrichidae, Neotropical primates). We repeatedly extracted the headspace above the samples and controlled for the delay between extractions. We compared the effect of different numbers of successive extractions, and different time periods at room temperature between extractions, on sample chemical richness, i.e. the number of compounds detected in the samples. Our objectives were: (1) to confirm that scent samples degraded over time and repeated extractions at room temperature; (2) to examine whether either the number of extractions or the time spent at room temperature had a greater effect on sample degradation or change; and 3 ) to describe the pattern of degradation for this type of sample.

\section{Materials and methods}

\subsection{Scent sample collection}

We collected naturally deposited scent-marks and urine from two captive emperor tamarins, Saguinus imperator, and four cotton-top tamarins, S. oedipus, at Drayton Manor Park (Staffordshire, UK), as part of a project investigating chemosignaling in these primates [7]. Sample collection was performed by swabbing the branch (usually a wet mark was visible), using a clean $1 \mathrm{~cm}^{2}$ square of viscose gauze held by clean forceps. Swabs were kept individually in clean $4 \mathrm{~mL}$ glass chromatography vials closed by a screw-top polytetrafluoroethylene septum lid. Both vials and swabs were washed in HPLC-grade methanol and pentane (ACROS Organics ${ }^{\mathrm{TM}}$, London, UK), then baked at $130{ }^{\circ} \mathrm{C}$ for $30 \mathrm{~min}$ prior to use, as recommended by Birkemeyer et al. [2]. After collecting the secretion, the swab was quickly returned to its vial and closed, and the forceps were wiped on clean gauze with pentane. Sample vials were kept in an insulated cool box filled with frozen gel packs at a temperature close to $0{ }^{\circ} \mathrm{C}$, then transferred to a freezer onsite $\left(-15^{\circ} \mathrm{C}\right)$ within two hours, where they remained for up to two months. Samples were then transported in the cool box to Anglia Ruskin University, where they were stored at $-80^{\circ} \mathrm{C}$ until analysis.

\subsection{Chemical analyses}

We analyzed samples using headspace solid-phase microextraction (SPME) and gas chromatography-mass spectrometry (GC-MS). Each sample was retrieved from the freezer immediately before analysis, and placed in a heat block at $40^{\circ} \mathrm{C}$ for an equilibration period of $10 \mathrm{~min}$. Samples were extracted using a $65 \mu \mathrm{m}$ PDMS/DVB StableFlex ${ }^{\mathrm{TM}}$ SPME fiber (Supelco, Bellefonte, PA, USA) for a period of $30 \mathrm{~min}$ at $40^{\circ} \mathrm{C}$. The sample-coated fiber was then manually injected at $250^{\circ} \mathrm{C}$ into the injection port of a Clarus 500 GC (PerkinElmer), fitted with a Thermogreen ${ }^{\circledR}$ LB-2 pre-drilled septum, and a splitless $1 \mathrm{~mm}$ liner. A flow of helium of $1 \mathrm{~mL} / \mathrm{min}$ was used as carrier gas. Splitless mode was applied for injection. A nonpolar capillary column, coated with $95 \%$ dimethyl- $/ 5 \%$ diphenyl-siloxane $(30 \mathrm{~m} \times 0.25 \mathrm{~mm} \times 0.25 \mu \mathrm{m}$ film thickness, Equity $^{\mathrm{TM}} 5$, Supelco) was used. The oven temperature program started at $40^{\circ} \mathrm{C}$, held for $2 \mathrm{~min}$, followed by an increase of $6^{\circ} \mathrm{C} / \mathrm{min}$ to the final temperature of $200^{\circ} \mathrm{C}$, held for $8 \mathrm{~min}$. A cool-down ramp was added, decreasing the temperature to $40^{\circ} \mathrm{C}$ at $20^{\circ} \mathrm{C} / \mathrm{min}$, and then held for $4 \mathrm{~min}$. The total run lasted $43 \mathrm{~min}$. The electron ionization Clarus 500 MS (PerkinElmer) was equipped with a quadrupole, and set to scan for mass-to-charge ratios between $41-300 \mathrm{~m} / \mathrm{z}$ after a 2 min delay. These scanning parameters were set after a refining process aimed to reduce baseline noise to a minimum. Before each sample was analyzed, the fiber was conditioned for $1 \mathrm{~min}$ at $250{ }^{\circ} \mathrm{C}$ in the injection port of the GC-MS; then a blank run (in which nothing was injected) was performed, to ensure the GC column was clean.

We analyzed the samples by SPME-GC-MS under three different experimental conditions. Each sample was analyzed between two and five times and was kept at room temperature (ca. $20^{\circ} \mathrm{C}$ ) between each analysis. Under the first condition, samples were analyzed five times, with short intervals between, at times $0 \mathrm{~h}, 1.5 \mathrm{~h}, 3 \mathrm{~h}, 4.5 \mathrm{~h}$, and $6 \mathrm{~h} .1 .5 \mathrm{~h}$ was the shortest time interval possible between analyses. Under the second condition, samples were analyzed five times, with longer intervals between, at times $0 \mathrm{~h}, 10 \mathrm{~h}, 24 \mathrm{~h}, 48 \mathrm{~h}$, and $72 \mathrm{~h}$. Under the third condition, samples were analyzed only twice at the maximum time interval, i.e. at times $0 \mathrm{~h}$ and $72 \mathrm{~h}$. Samples from the different individuals were blindly assigned to one of the three experimental conditions tested; six samples were run under each condition. We treated each scent-mark collected as an independent sample because we assumed that two marks from the same individual may differ in their amount and chemical composition. Moreover, the amount of secretion left by the animals was usually too small to take more than one swab per mark. 
For each GC-MS chromatogram, automatic peak detection, integration, and tentative identification using the National Institute of Standards and Technology (NIST) mass spectral library [8] was performed in ChemStation ${ }^{\mathrm{TM}}$ (Agilent, Santa Clara, CA, USA). Only peaks with a minimum height of $1 \%$ of that of the largest peak were selected, in order to limit the inclusion of background noise. All detected peaks were listed using the information of retention time, peak area and height, and mass spectrum. Tentative names were assigned to compounds after NIST mass spectral library search if the identity match was over $80 \%$. The identities of seven compounds were further confirmed by comparison of their retention times with those of commercially obtained compounds, analyzed under identical conditions.

\subsection{Statistical analyses}

All statistical analyses were performed in R v.3.5.1 operated in RStudio [9]. A generalized linear mixed model with Poisson family and log link function (glmer function in $\mathrm{R}$ package Ime4 [10]) was built to assess the effect of experimental conditions on sample chemical richness. The fixed effects in the model were delay between extractions and number of extractions; and the random effects were the individual tamarin sampled and sample ID (nested into individual), to account for repeated extractions of the same sample. Determination of the variance inflation factor (vif function in R package car [11]) revealed collinearity

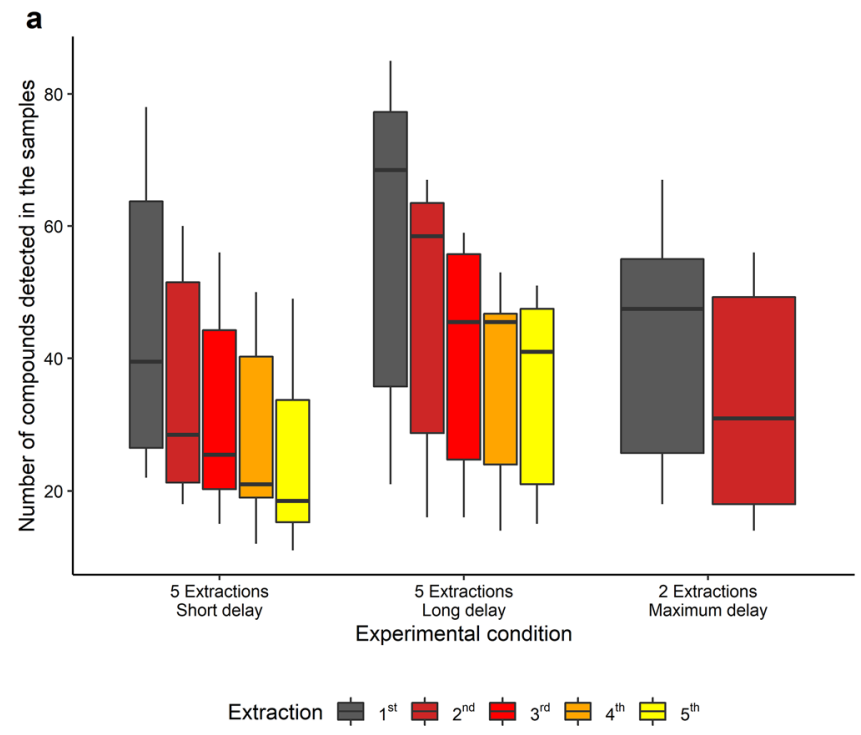

Fig. 1 a Variation in the number of compounds detected in samples tested under three experimental conditions: samples extracted five times at short (1.5 h), and long (10-24 h) intervals, and samples extracted twice at maximum interval $(72 \mathrm{~h})$. Boxes indicate the median and interquartile range (IQR); whiskers give the when adding interaction terms between the two fixed effects; for this reason interactions were removed from the model. Visual inspection of residual plots, produced using simulateResiduals and testResiduals functions in $\mathrm{R}$ package DHARMa [12], did not reveal any obvious heteroscedasticity or overdispersion in the data.

Looking solely at changes in sample chemical richness would fail to take into account the possible appearance over time and repeated extractions of new compounds, resulting from bacterial activity or other chemical reactions inside the sample vial at room temperature. Therefore, we subsequently recorded, from the total compounds detected in the different experimental conditions, the lost compounds, i.e. compounds present in the sample at first extraction but absent at any of the following extractions; and the gained compounds, i.e. compounds not present at first extraction and appearing at one of the following extractions.

\section{Results}

We observed a decrease in sample chemical richness, i.e. the loss of compounds, after first extraction, and at each following extraction, under all three conditions (Fig. 1a). The generalized linear mixed model showed a significant effect of the number of extractions on sample chemical richness, even at the second extraction ( 1 st-2nd extraction: $Z=-4.51 ; P<0.01$; Supplementary Table $S 1)$.

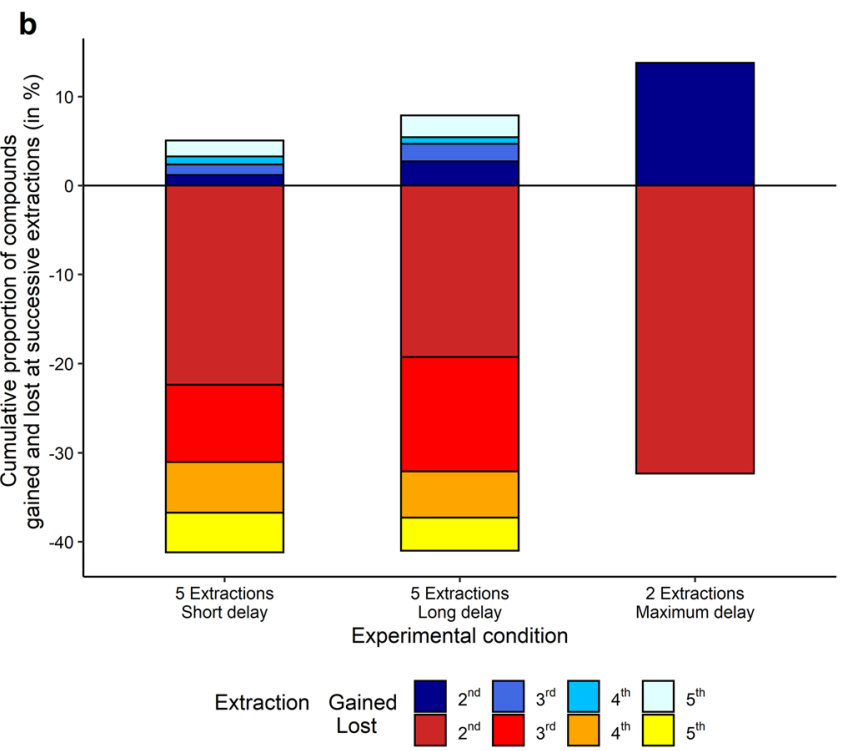

smallest value $\geq$ lower hinge $-1.5^{*} \mathrm{IQR}$, and largest value $\leq$ upper hinge $+1.5^{*} \mathrm{IQR}$; b Cumulative proportion of compounds gained (positive values), and lost (negative values), at each successive extraction for the three experimental conditions 
Conversely, we found no significant difference between experimental conditions, i.e. the total number of extractions or delay between extractions (5 extractions short delay-2 extractions maximum delay: $Z=0.73 ; P=0.47$; 5 extractions short delay-5 extractions long delay: $Z=-0.25 ; P=0.80$; Supplementary Table $S 1$ ).

While up to $41 \%$ of compounds $(n=138$ and $n=166$ for samples extracted five times at short and long interval respectively) present at first extraction were lost over time, new compounds represented over $5 \%(n=17$ and $\mathrm{n}=32$ for samples extracted five times at short and long interval respectively) of the total compounds detected in the samples (Fig. 1b). Measures of gained and lost compounds when only two extractions were performed were probably overrepresented, since it was not possible to distinguish between genuinely gained or lost compounds, and possible artifacts from the analyses.

We tentatively identified a number of the compounds having been gained, or lost, at second or third extraction (Table 1). Identities of hexanal, butanoic acid, 1,2-dimethylbenzene, heptanal, 6-Methyl-5-hepten-2one, hexanoic acid and octanoic acid were confirmed by comparison of their retention times with those of commercially obtained compounds analyzed under the same SPME-GC-MS conditions.

Table 1 Subset of the compounds lost and gained at second or third extraction of the same samples. Tentative names were given by NIST mass spectral library search, with identity match $\geq 80 \%$

\begin{tabular}{lll}
\hline Lost / Gained & $\begin{array}{l}\text { Average reten- } \\
\text { tion time } \\
\pm \text { SD }(\mathrm{min})\end{array}$ & Tentative identification \\
\hline Lost & $6.16 \pm 0.01$ & Hexanal* $^{*}$ \\
& $9.00 \pm 0.00$ & 1,2-Dimethylbenzene* \\
& $9.35 \pm 0.01$ & Heptanal* $^{*}$ \\
& $12.00 \pm 0.01$ & 6-Methyl-5-hepten-2-one* \\
& $13.11 \pm 0.00$ & D- or L-Limonene \\
& $14.88 \pm 0.01$ & 2-Methoxyphenol \\
& $17.63 \pm 0.00$ & Methyl salicylate \\
& $6.45 \pm 0.02$ & Butanoic acid* \\
Gained & $7.55 \pm 0.03$ & 4-Hydroxypentan-2-one \\
& $12.13 \pm 0.05$ & Hexanoic acid* \\
& $13.47 \pm 0.01$ & 3,3,5-Trimethylcyclohexanone \\
& $14.74 \pm 0.01$ & Heptanoic acid \\
& $17.14 \pm 0.01$ & Octanoic acid* \\
& $21.73 \pm 0.00$ & 2,6,10-Trimethyldodecane \\
\hline
\end{tabular}

Identity of the seven compounds marked with an asterisk was confirmed by comparison of their retention times with those of commercially obtained compounds

$\mathrm{SD}=$ standard deviation

\section{Discussion}

In this experiment we observed the loss of over $40 \%$ of compounds in tamarin scent samples over time. We found no evidence that long delays at room temperature (ca. $20^{\circ} \mathrm{C}$ ) affected sample chemical composition more than short delays, which implies that temperature may not directly impact sample quality to a damaging level, as was previously thought. Nevertheless, the delays at room temperature used in this experiment did not exceed $72 \mathrm{~h}$. This amount of time might be sufficient for transporting animal scent samples between the collection site and the laboratory when these are in the same geographical region. In the case of many field studies, however, the duration of sample storage and transportation can often stretch to several weeks or even months, which constitutes an important challenge [5]. In this case, resorting to on-site freezing and temperaturecontrolled shipment (e.g. dry ice), thermally stable sampling methods, or field-based chemical analyses remains a requirement for high-quality results [3].

We also showed that repeated extraction of a sample enhanced the loss of compounds. Reade et al. [13], in a thorough methods optimization of SPME-GC-MS analyses of murine and human fecal volatile organic compounds, have similarly reported a significant decrease in the number of compounds after successive extractions of a single sample. The fact that some compounds were undetectable after first or second extraction may be explained by the very small amount of scent sample removed and the low concentrations of compounds within the sample. Moreover, as the SPME desorption method requires the sample to be heated to $40{ }^{\circ} \mathrm{C}$ for $10 \mathrm{~min}$ at each extraction, it is likely that a number of highly volatile compounds were lost from the sample at successive extractions. Such findings highlight the importance of using particularly sensitive analytical methods when investigating animal scents, as many compounds of high volatility and/or low concentration might be missed [5].

Samples also gained new compounds over time, with over $5 \%$ of compounds newly appeared after successive extractions. These new compounds are likely to derive from the degradation of existing compounds at room temperature, and the action of microorganisms inside the sample container [4]. Some of the newly gained compounds appeared to be derived by chemical reaction from other compounds also identified in the secretion. For instance, while hexanoic acid and heptanoic acid appeared at the second extraction, hexanal and heptanal disappeared. It is probable that hexanal and heptanal have been oxidized to their corresponding 
carboxylic acids via bacterial activity inside the vial when left at room temperature. Other compounds, such as 2-methoxyphenol, are quite reactive when exposed to air and light, and would have naturally degraded when left at room temperature [14]. Although these changes occurred in the laboratory, it is likely that such changes will contribute to the natural aging of samples, which could itself be of semiochemical importance [6]. In the wild, the progressive change in chemical composition of a secretion would be reflected in an altering odor profile and would relate to the time elapsed since the signaler animal was physically present in the area [15].

Our results showed that repeated sampling of the headspace above a sample has a more deleterious effect on the quality of the sample than storage at room temperature for periods up to $72 \mathrm{~h}$. Nonetheless, the changes in sample chemical composition observed over time in this experiment support the recommendation made by many researchers in the field of animal chemosignaling to avoid storing samples for long periods at room temperature and to extract each sample only once.

Acknowledgements We thank the British and Irish Association of Zoos and Aquariums, as well as the research coordinator and zookeepers at Drayton Manor Park for their help and support. We are grateful to S. Vaglio from University of Wolverhampton for the loan of equipment.

Funding Funding was provided to ACP by a PhD studentship from Anglia Ruskin University.

Data availability The data and $\mathrm{R}$ code supporting this article can be obtained from https://github.com/AlicePoirier/Poiri er_et-al._SNAS_2021.

\section{Declarations}

Conflict of interest The authors declare that they have no conflict of interest.

Ethical approval This project was approved by the Faculty of Science and Engineering Departmental Research Ethics Panel at Anglia Ruskin University and received support from the British and Irish Association of Zoos and Aquariums. It adheres to the American Society of Primatologists Principles for the Ethical Treatment of Non-Human Primates, and follows the Animal Behavior Society Guidelines and the American Society of Mammalogists' Guidelines on wild mammals in research.

Open Access This article is licensed under a Creative Commons Attribution 4.0 International License, which permits use, sharing, adaptation, distribution and reproduction in any medium or format, as long as you give appropriate credit to the original author(s) and the source, provide a link to the Creative Commons licence, and indicate if changes were made. The images or other third party material in this article are included in the article's Creative Commons licence, unless indicated otherwise in a credit line to the material. If material is not included in the article's Creative Commons licence and your intended use is not permitted by statutory regulation or exceeds the permitted use, you will need to obtain permission directly from the copyright holder. To view a copy of this licence, visit http://creativecommons .org/licenses/by/4.0/.

\section{References}

1. Wyatt TD (2014) Pheromones and animal behaviour, 2nd edn. Cambridge University Press, Cambridge

2. Birkemeyer CS, Thomsen R, Jänig S et al (2016) Sampling the body odor of primates: cotton swabs sample semivolatiles rather than volatiles. Chem Senses 00:1-11. https://doi. org/10.1093/chemse/bjw056

3. Kücklich M, Möller M, Marcillo A et al (2017) Different methods for volatile sampling in mammals. PLoS ONE 12:1-18. https:// doi.org/10.1371/journal.pone.0183440

4. Charpentier MJE, Barthes N, Proffit M et al (2012) Critical thinking in the chemical ecology of mammalian communication: roadmap for future studies. Funct Ecol 26:769-774. https://doi. org/10.1111/j.1365-2435.2012.01998.x

5. Drea CM, Boulet M, Delbarco-Trillo J et al (2013) The "secret" in secretions: Methodological considerations in deciphering primate olfactory communication. Am J Primatol 75:621-642. https ://doi.org/10.1002/ajp.22143

6. Alberts AC (1992) Constraints on the design of chemical communication systems in terrestrial vertebrates. Am Nat 139:62-89

7. Poirier AC (2019) Scent-marking behaviour and semiochemistry in the Callitrichidae. Anglia Ruskin University, Cambridge, UK

8. Shen VK, Siderius DW, Krekelberg WP, Hatch HW (2014) NIST Standard Reference Simulation Website, NIST Standard Reference Database Number 173. In: Natl. Inst. Stand. Technol

9. R Core Team (2020) R: A language and environment for statistical computing

10. Bates D, Mächler M, Bolker BM, Walker SC (2015) Fitting linear mixed-effects models using Ime4. J Stat Softw. https://doi. org/10.18637/jss.v067.i01

11. Fox J, Weisberg S (2019) An R companion to applied regression, 3rd edn. Sage, Thousand Oaks CA

12. Hartig F (2020) DHARMa: Residual Diagnostics for Hierarchical (Multi-level / Mixed) Regression Models. R package version 0.3.1.

13. Reade S, Mayor A, Aggio R et al (2014) Optimisation of sample preparation for direct SPME-GC-MS analysis of murine and human faecal volatile organic compounds for metabolomic studies. J Anal Bioanal Tech. https://doi.org/10.4172/21559872.1000184

14. Royal Society of Chemistry (2020) ChemSpider Search and Share Chemistry. http://www.chemspider.com/

15. Müller-Schwarze D (2006) Chemical ecology of vertebrates. Cambridge University Press

Publisher's Note Springer Nature remains neutral with regard to jurisdictional claims in published maps and institutional affiliations. 